\title{
Anti-herbivore factors of grass endophytes: new prospects from metabolomics
}

\author{
G.A. LANE ${ }^{1}$, M. CAO ${ }^{1}$, L.J. JOHNSON ${ }^{1}$, A. KOULMAN ${ }^{1}$, A.J. POPAY ${ }^{2}$, S. RASMUSSEN ${ }^{1}$ and B.A. TAPPER ${ }^{1}$ \\ ${ }^{1}$ AgResearch, Grasslands Research Centre, PB 11008, Palmerston North \\ ${ }^{2}$ AgResearch, Ruakura Research Centre, PB 3123, Hamilton 2015
}

geoff.lane@agresearch.co.nz

\begin{abstract}
A defensive role for several of the major alkaloids of Neotyphodium spp. endophytes in forage grasses has been confirmed in genetic experiments. However, many aspects of the activity of endophyte-infected grasses towards herbivores remain unaccounted for, suggesting there are further anti-herbivore factors yet to be uncovered. The development of metabolomics has provided new tools for the discovery of novel metabolites without preconceptions of the likely chemical structural class. Prospects for the application of new methods from metabolomics to further elucidate the defensive chemistry of associations of Neotyphodium spp. endophytes with their grass hosts are reviewed.
\end{abstract}

Keywords: Neotyphodium, Epichloë, defensive chemistry, invertebrate, vertebrate, gene deletion

\section{Introduction}

The development and commercial release of associations of selected endophytes with improved cultivars of forage grasses (Bouton \& Easton 2004; Easton et al. 2001) provides an object lesson in how discoveries of natural mechanisms of chemical defence against herbivores can be manipulated to advance agricultural technology. However, while evidence of the defensive chemistry of symbioses of fungal endophytes of Neotyphodium spp. with host grasses of the Poaceae and their anti-herbivore effects has accumulated over some 25 years (below), many effects remain unaccounted for.

For example, some endophyte strains have been found to suppress root-feeding aphids (Aploneura lentisci) on perennial ryegrass (Popay et al. 2004), while the major known alkaloids are largely confined to the above-ground parts of the plant (Lane et al. 2000), and the relationship between the known alkaloid chemotype of endophyte strains and their in planta activity against insects is in many cases unclear. Thus the $N$. lolii strain AR1 in perennial ryegrass affords some resistance

Figure 1 Scheme outlining potential applications of metabolomics research tools to the discovery of novel antiherbivore factors.

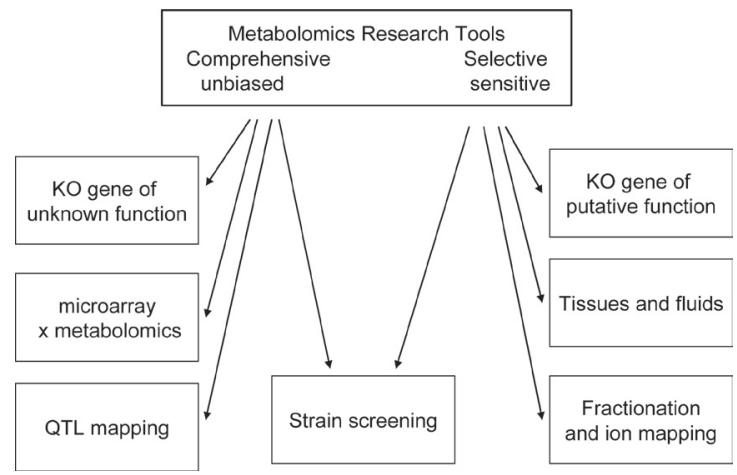

against black beetle (Heteronychus arator) (Popay \& Baltus 2001) despite the absence of ergovaline to which this insect is known to be sensitive (Ball et al. 1997), and the effects on feeding and development of Spodoptera frugiperda larvae of different endophyte strains in three different host grasses could not be accounted for by the activity of the known endophyte alkaloids in these associations (Ball et al. 2006). Likewise, the chemical basis of resistance of endophyte-infected perennial ryegrass to pasture mealybug (Balanococcus poae) (Pennell et al. 2005) remains to be identified. Elucidation of the chemistry underlying these defensive mechanisms offers the prospect of new opportunities for developing endophyte-grass associations with improved characteristics for agriculture.

These examples focus on insect herbivores. While there is strong indicative evidence that several of the known endophyte alkaloids play a defensive role against mammalian herbivores (Siegel \& Bush 1996), as with insects, there is certainly the possibility that other endophyte metabolites as yet undiscovered affect livestock performance.

The new technologies and approaches to investigating plant and fungal metabolites now being developed in metabolomics provide new opportunities for uncovering novel defensive chemistry in grass-endophyte symbioses. Metabolomics has been developed as part of the suite of tools of functional genomics to reveal the links between genes and metabolic phenotypes. As originally defined it is comprehensive analysis in which all the metabolites of an organism are identified and quantified (Fiehn 2002). Given the chemical diversity and wide dynamic range of metabolites this remains an elusive goal. In current practice metabolomics involves the application of broad-ranging analytical methods to provide insights into gene function. The ambition of metabolomic

Figure 2 Dendrogram of correlations between relative levels of known and putative novel indolediterpenoid metabolites detected by LC-MS/MS analysis in ryegrass plants infected with wild-type Epichloe fesctucae Fl1 or with either of two strains with deletions in the sidF gene. Metabolites highly correlated with lolitrem B show a similar pattern of elevated accumulation in plants infected with the sidF deletion strains.

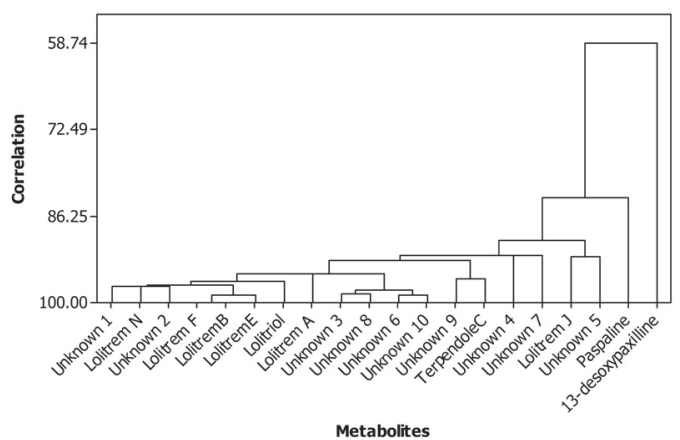


Figure 3 Expression of four ESTs and lolitrem $B$ in different tissue types ( $B=$ blade, $I=i m m a t u r e, ~ S=s h e a t h)$ from four replicate samples of uninfected perennial ryegrass (E-) or ryegrass infected with Neotyphodium Iolii strain Lp19 (E+).

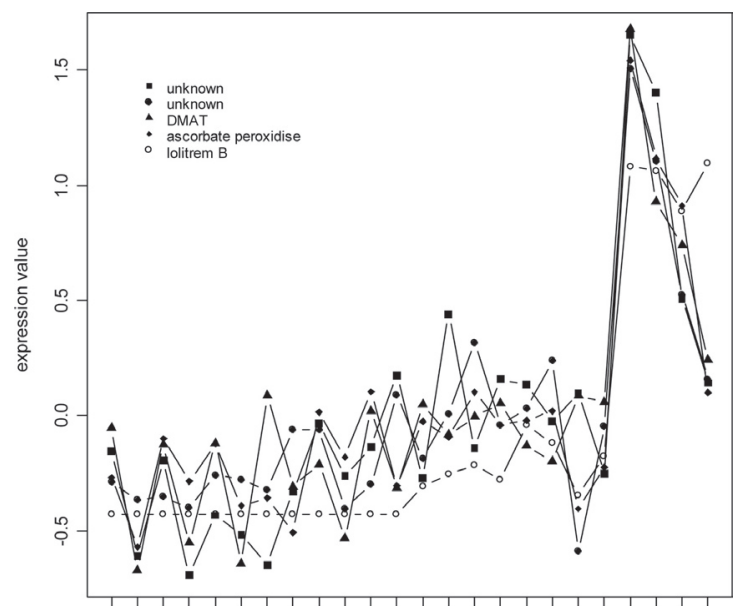

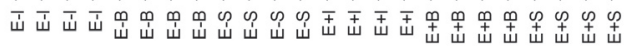
treatment

analysis to achieve comprehensive coverage is of particular relevance in this context as it has provided the impetus for new approaches to "untargeted" and "unbiased" analysis.

These metabolomics methods offer the prospect of an unblinkered view of the metabolites in a biological system, unconstrained by the preconceptions of the experimentalist. In the context of anti-herbivory factors of grass-endophyte systems they thus can provide opportunities for discovering entirely new classes of defence metabolites. However, if comprehensive unbiased analysis can be achieved, not all components will be of equal relevance in any specific context. The challenge thus becomes extracting from the mass of data the information that is most biologically relevant to the question at hand, and along with new analytical technologies, the tools of multivariate statistical analysis are a vital component of metabolomics.

As a prelude to considering the potential role of metabolomics in extending current knowledge of anti-herbivore factors of grass-endophyte symbioses it is worth briefly recapping the path to discovery of the major known anti-herbivory factors, and recent contributions from molecular genetics to the elucidation of their role.

\section{Discovery of Anti-Herbivory Factors}

The discovery of the known anti-herbivore factors of grassendophyte symbioses has encompassed a sequence of revelations of effects and discovery of their putative causative agents. While grass-endophyte symbioses have evidently persisted in their endemic environments, it was only many years after the introduction of forage grasses infected with fungal endophytes of Neotyphodium spp. into "New World" agricultural systems that the role these fungi can play in defending their grass host from herbivores drew the attention of agricultural scientists. Thus nearly 30 years ago the association of Neotyphodium endophytes with symptoms of "fescue toxicosis" (Bacon et al. 1977; Hoveland et al. 1980) and later "ryegrass staggers" (Fletcher \& Harvey 1981) was revealed and the defensive chemistry of grass-endophyte symbioses was subsequently uncovered.
The pioneering investigations of the chemistry of grass endophytes described four classes of alkaloids biosynthesised by Neotyphodium spp. fungi in their grass hosts: pyrrolizidine alkaloids of the loline family (Bush et al. 1993); ergot alkaloids, particularly ergovaline (Garner et al. 1993); indolediterpenoids, particularly lolitrem B (Gallagher et al. 1981; Munday-Finch et al. 1998 and references cited): and the pyrrolopyrazine peramine (Rowan \& Gaynor 1986). For each of these classes evidence was obtained suggesting they play a role in defending the symbiosis against herbivores whether vertebrate (Siegel \& Bush 1996) or invertebrate (Popay \& Bonos 2004).

In the case of loline alkaloids, peramine and ergot alkaloids, genetic evidence of their significance as defensive compounds is now available. The asexual nature of Neotyphodium endophytes has limited conventional genetic studies. However, direct evidence for the defensive significance of loline alkaloids has been provided by Mendelian genetic analysis of progeny of loline alkaloid expressing and non-expressing chemotypes of the sexual endophyte Epichlöe festucae (Wilkinson et al. 2000). Loline alkaloid expression was found to segregate 1:1 between progeny and co-segregate with activity against two aphid species, and in planta levels of the alkaloids were correlated with antiaphid activity.

With recent progress in dissecting the molecular genetics of endophyte alkaloid biosynthesis, genetic analysis is now being applied to the elucidation of defensive mechanisms of Neotyphodium endophytes. The defensive role of peramine against adult Argentine stem weevils (Listronotus bonarienesis) has recently been directly confirmed by gene deletion studies. A non-ribosomal peptide synthetase gene, perA was identified in Epichlöe festucae strain F11 as essential for the synthesis of peramine in planta (Tanaka et al. 2005). In a feeding choice assay, feeding by adult weevils was much higher on leaf blades of perennial ryegrass infected with a per $A$ deletion mutant strain than on leaf blades from plants infected with the wild-type strain, and comparable to that on blades from uninfected plants.

Similarly, direct evidence of the effects of endophyte ergot alkaloids on a mammalian herbivore (rabbits) has been provided by studies with two mutant endophyte strains with gene deletions early and late in the ergot alkaloid pathway (Panaccione et al. 2006a). While the ingestion of ergovaline reduced appetite, the production of ergot alkaloids earlier in the pathway (clavines) reduced preference. However, when the entire alkaloid pathway was eliminated, rabbits unexpectedly preferred endophyte-infected plants, and the basis for this remains unknown. Conversely, experiments with these deletion mutants have eliminated ergot alkaloids as a factor responsible for the suppression of infection of endophyte-infected perennial ryegrass by the lesion nematode Pratylenchus scribneri (Panaccione et al. 2006b). While ergovaline suppressed nematode motility in a laboratory bioassay, nematode infection was inhibited in endophyte-infected plants whether the endophyte strain was the wild-type, or a mutant with a gene deletion early or late in the ergot alkaloid pathway. Thus gene deletion studies can expose evidence of as yet uncharacterised defensive factors as well as better defining the role of known ones.

Clearly there are opportunities for extending these studies to a wider range of herbivores, and to other pathways, notably indolediterpene biosynthesis. There is also the potential for the identification of novel defensive metabolites by the combination of gene deletion experiments and metabolomics (below).

Attempts to define the defensive role of particular metabolites or classes of metabolites by comparative studies of grassendophyte associations using selected fungal strains from nature 
Figure 4 Mass spectrometric fingerprint of an extract of seed of perennial ryegrass infected with the AR1 endophyte, showing detection and collision-induced fragmentation of ion of $\mathrm{m} / \mathrm{z} 248$ (peramine).

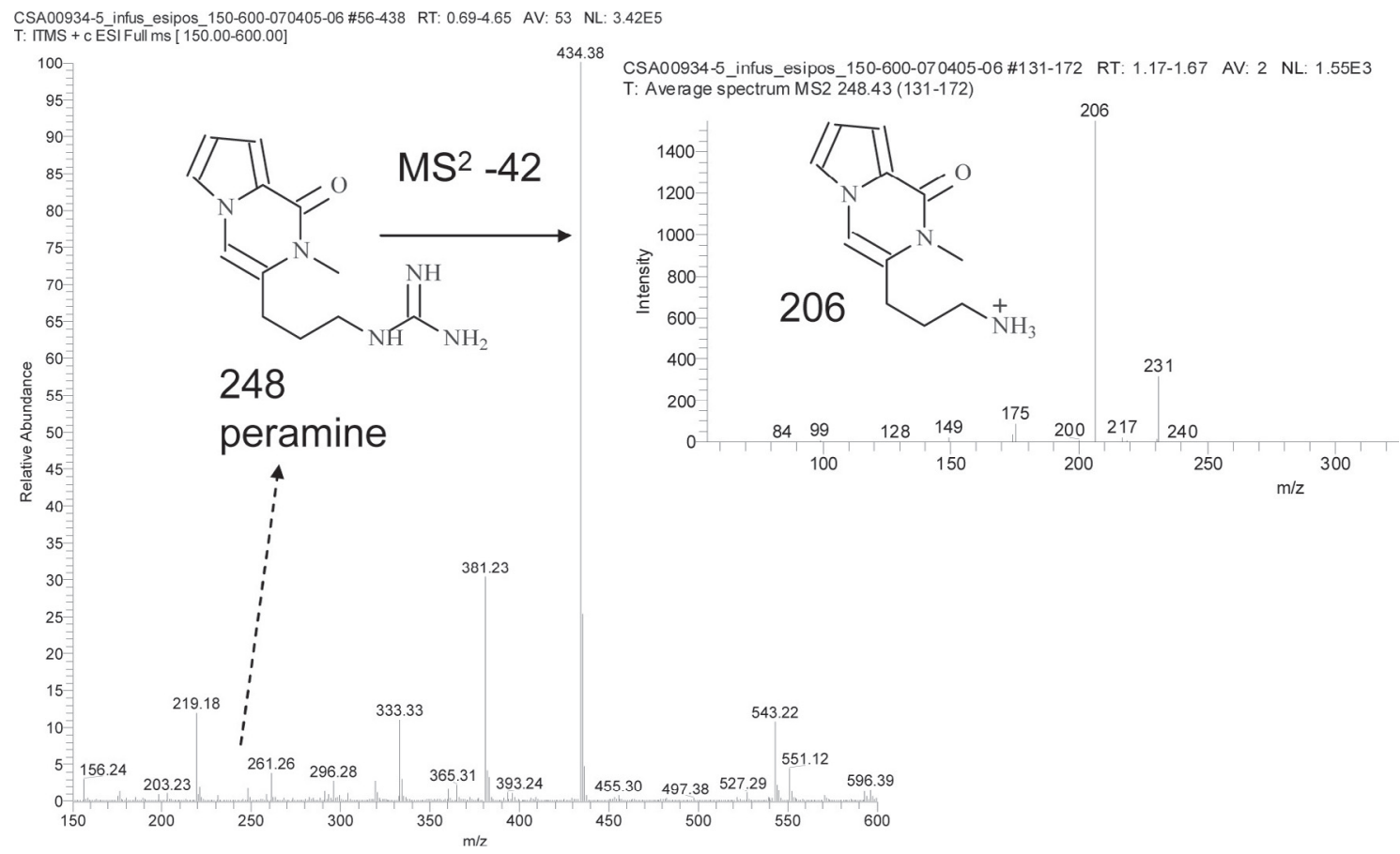

which produce or do not produce them have been less conclusive as they are likely to be confounded by variations in other endophyte (or plant) metabolites. In practice this has proved to be a valuable route for discovering new variants of endophyte alkaloid biosynthesis. Thus, the unexpected insect resistance and performance in the field of ryegrass associations with the AR37 endophyte (Popay \& Wyatt 2005) led to the discovery of a new class of endophyte indolediterpenoids, the epoxy-janthitrems (Tapper \& Lane 2004). Similarly, comparisons of the effects of high ergovaline and low ergovaline strains of Neotyphodium sp. endophytes in tall fescue drew attention to the clavine alkaloids, particularly setoclavine and isosetoclavine present in the "Claviplus" endophytes (Tapper et al. 2002). Further investigation of grass associations with Neotyphodium endophyte strains that do not produce appreciable concentrations of known defensive chemicals is likely to uncover further components of their defensive armoury.

There is also considerable scope for expanding knowledge of the range of antiherbivory factors of Neotyphodium spp. and related endophytes by applying more research effort to exploring associations with grasses beyond the predominant commercially important forage species. Thus, the nature of the indolediterpenoids suggested by ELISA investigations to be present in Neotyphodium spp associations with Echinopogon ovatus, Melica decumbens, and Poa huecu (Miles et al. 1998; Towers 1997) remains to be elucidated.

\section{Potential Role of Metabolomics}

There are several routes by which metabolomics with the combination of comprehensive approaches to analysis and multivariate statistical tools can potentially aid in the discovery of new anti-herbivore metabolites and indeed classes of metabolites
(Fig. 1). These include gene-focussed approaches such as comprehensive metabolomic analysis of gene knockouts, and the combination of metabolomics with transcriptome (microarray) analysis, and also approaches where comprehensive and sensitive analytical technologies are to the forefront.

One of the key roles of metabolomics in functional genomics from its inception has been in elucidating the metabolic outcome of gene deletions (e.g. Raamsdonk et al. 2001). The comparative examination of metabolite profiles of host grass associations with wild type and mutant endophyte strains with deletions in putative secondary metabolite biosynthesis genes is a potential route to the discovery of new metabolites. Such an approach could also provide the experimental material for unambiguous evaluation of defensive function as in the examples above. However, its efficacy will be entirely dependent on the prior identification of a key regulatory or biosynthetic gene for such a metabolite.

The investigation of genes of unknown role has provided new insights into the grass-fungus symbiosis through the construction and introduction to plants of mutant endophytes with deletions in genes which are evidently vital to the stability of the symbiosis, namely noxA, a NADPH oxidase gene (Tanaka et al. 2006) and $s i d F$, a gene for a non-ribosomal peptide synthetase involved in the biosynthesis of a novel siderophore (Johnson et al. 2007). These studies have revealed the importance of reactive oxygen species (ROS) and Fe regulation, respectively, to the symbiosis, and also the vital role bioactives produced by the endophyte may play apart from plant defence (Johnson et al. 2007). Reports of the discovery of new defensive metabolites identified by this route are awaited.

However, new putative defence factors may also be revealed by the unexpected effects of gene deletions. Thus a novel clavine, 6,7-secolysergine was found to accumulate to unusually high levels in a ryegrass plants infected with mutant strain of 
Figure 5 Plot of discriminant function scores (DF1, DF2, DF3) from multivariate analysis of data from Direct Infusion Mass Spectrometric analysis of extracts of samples of seeds of perennial ryegrass without endophyte (squares) or infected with a common toxic endophyte (diamonds) or the selected strains AR1 (triangles) or AR542 (circles). The semi-filled symbols are projections of the loadings on the discriminant functions of the $\mathrm{m} / \mathrm{z} 248$ ion (square: peramine), $\mathrm{m} / \mathrm{z} 183$ ion (diamond: $\mathrm{N}$-acetyl-norloline), and $\mathrm{m} / \mathrm{z} 534$ ion (circle; ergovaline).

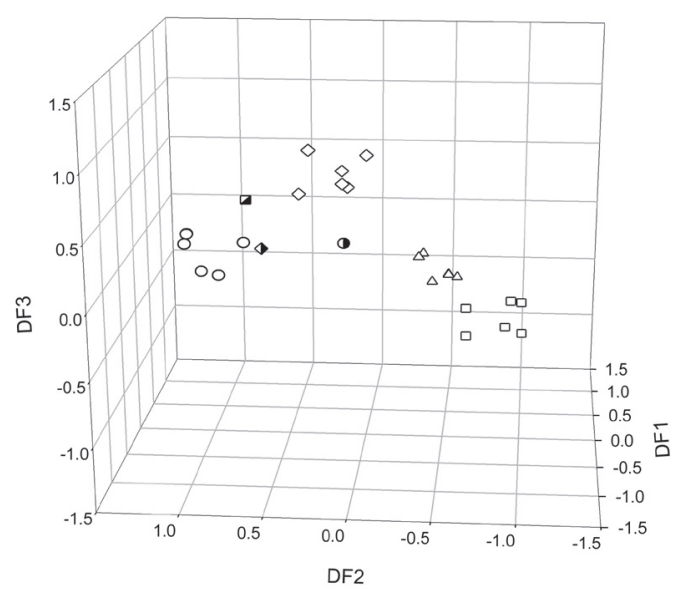

Neotyphodium sp. Lp1 with a deletion of the gene $\operatorname{lps} A$ for the final non-ribosomal peptide synthetase for the biosynthesis of ergovaline (Pannacionne et al. 2003), and was subsequently found to be a constituent of plants infected with the wild-type strain. Recently we examined plants infected with mutant strains of E. festucae Fl1 with a deletion in the sidF gene that accumulate high levels of peramine, ergovaline and lolitrem B (L. Johnson unpublished). HPLC-MS/MS screening revealed a range of other indolediterpenes also accumulated at high levels in these plants, including several apparently novel compounds (Fig. 2). These effects on endophyte alkaloid biosynthesis may be mediated by the unusual interaction between the sidF deletion strains and their plant hosts (Johnson et al. 2007).

The investigation of grass-endophyte symbioses by joint metabolomics and transcriptomics provides another potential route for the discovery of novel anti-herbivore factors. Multivariate statistical analysis of data from microarray analysis of fungal gene expression in plant tissues together with metabolomic data can reveal associations between gene expression and metabolite accumulation. Thus the pattern of expression of four ESTs was found to co-cluster with lolitrem B levels in a joint analysis (Cao et al. 2007). These ESTs were highly up-regulated in the mature tissue (ryegrass sheath) of endophyte-infected ryegrass, where lolitrem B accumulation was greatest (Fig. 3). Of these ESTs one is homologous to a dimethylallyltryptophan synthase gene in the lolitrem biosynthetic gene cluster in N. lolii (Young et al. 2006), and another to an ascorbate peroxidase, while no homologues were found for the other two genes. Expression patterns of putative genes for other biosynthetic processes may provide leads to new classes of metabolites that may not be evident in a broad metabolomic analysis, but may be uncovered by appropriately targeted sensitive analytical methods.

The "comprehensive" analyticalmethodologies of metabolomics can be applied beyond functional genomics. Recently a range of grass-endophyte associations have been investigated by Direct Infusion Mass Spectometric Fingerprinting of seed extracts (Koulman et al. 2006b). Over 600 ions could be detected in each sample, and collision-induced fragmentation data were collected on the most intense 200 ions in each sample. The "fingerprint" data were analysed by multivariate statistics and the features (ions) showing the greatest differential between sample classes (endophyte strains) identified. In some cases these could be directly identified as known endophyte alkaloids by their characteristic fragmentation pattern (e.g. Fig. 4). Analysis of a subset of the data for grass-endophyte associations producing the known major alkaloids demonstrated that ions for these alkaloids were dominant discriminating features between these associations (Fig. 5). Thus peramine $(\mathrm{m} / \mathrm{z} 248)$ was a feature discriminating endophyte-infected from uninfected plants, N-acetyl-norloline $(\mathrm{m} /$ $z$ 183) discriminated plants infected with AR542, and ergovaline $(\mathrm{m} / \mathrm{z} 534)$ the plants infected with a common toxic strain. Analysis of the full data set revealed apparently new classes of metabolites in selected Neotyphodium spp. strains and the occurrence of these mapped to clades in a gene-marker-based phylogeny (Koulman unpublished). Among these selected strains are several for which interesting patterns of activity against insects have been observed in planta despite the absence of the major known alkaloids (A.J. Popay unpublished). Further investigation may well reveal new aspects of the defensive chemistry of Neotyphodium.

While these investigations were carried out on a range of endophyte strains in different plant hosts, the investigation of synthetic populations of known endophyte strains in progeny of defined host grass parents is also potentially fruitful. The relative production of different endophyte alkaloids has been found to vary widely with the same strain of endophyte in different host genotypes (Spiering et al. 2005). Although the endophyte strain in a progeny population is defined by maternal inheritance, the amounts of endophyte mycelium and relative levels of alkaloids have been shown to be heritable genetic characteristics of the host (Easton et al. 2002). Recently the variation of leaf metabolites in a mapping population of perennial ryegrass infected with a common toxic endophyte has been investigated by direct infusion MS/MS. QTL analysis has revealed loci controlling ergovaline and peramine levels in leaf tissue (Faville et al. 2007). Similar variations in the relative production of as yet unknown endophyte alkaloids or other defensive metabolites are likely to occur within the population, and this methodology has the potential to discover them and link them directly to loci. Further, by coupling measurements of insect resistance with metabolic profiling in a QTL analysis, direct links may be established between novel metabolites, their underlying genes, and their role in insect resistance, as has been demonstrated by Kliebenstein and co-workers in Arabidopsis thaliana (Zhang et al. 2006).

An early outcome of the acquisition of the powerful and sensitive analysis tools required for metabolomics has been expansion of knowledge of known classes of endophyte metabolites. HPLCMass Spectrometry /Mass Spectrometry using ion-trap detection has proved a powerful tool for the analysis of indolediterpenoids providing high sensitivity and selectivity for a wide range of structural types, and valuable characterising data in the patterns of collision-induced fragmentation in the ion trap (or source). Investigations of a range of grass-endophyte associations, both lolitrem B producers and non-producers have revealed that the "minor" indolediterpenoids previously reported from seed of perennial ryegrass infected with common strains of $N$. lolii (Munday-Finch et al. 1998; Gatenby et al. 1999), in particular the terpendoles, are fairly widely distributed, providing further 
evidence that the absence of lolitrem B does not imply the absence of indolediterpenoids (B.A. Tapper unpublished). The defensive role of these compounds remains to be clarified, and gene deletion technology is probably the most powerful option now available.

The sensitivity of HPLC-MS/MS is also providing new insights into the distribution of endophyte alkaloids within the grass plant. The recent detection in gutation fluid from endophyte-infected grass plants, of peramine from perennial ryegrass plants and also ergovaline and lolines in the case of tall fescue plants (Koulman et al. 2006a; Koulman et al. 2007) opens up interesting questions about the significance of this process to plant defence. This technology may also be valuable in elucidating the mechanisms by which endophytes afford protection against root-fee ding insects.

There are further opportunities as yet unexplored for applying metabolomics methodologies to the discovery of new antiherbivore factors in grass-endophyte associations. Bioassaydirected discovery is a powerful but laborious approach to the identification of unknown bioactives. By introducing methodology from metabolomics it may be possible to accelerate the process by comparative metabolite profiling and bioassay of fractions, for example, with ELISA assays for compound classes, applying multivariate statistics to identify the features associated with high activity early in the separation process. Using MS/MS ion-mapping methodologies it may be possible to discover highly active minor constituents within complex fractions. However, no equivalent short-cuts are evident to the laborious task of isolating active compounds to verify their activity.

Despite more than 20 years of research into and exploitation of the defensive chemistry of associations of endophytic Neotyphodium spp. fungi more opportunities remain. With new analytical approaches from metabolomics, new advances in functional genomics, and the energies of a new generation of researchers there are excellent prospects for further significant advances in endophyte technologies.

\section{ACKNOWLEDGEMENTS}

We acknowledge the skilled technical support of Karl Fraser and Millie Yu in carrying out this research, and funding support from the New Zealand Foundation of Research Science and Technology under contract C10X0203 "New opportunities from Forage Plant Genomics".

\section{REFERENCES}

Bacon, C.W.; Porter, J.K.; Robbins, J.D.; Luttrell, E.S. 1977. Epichloe typhina from toxic tall fescue grasses. Applied and Environmental Microbiology 34: 576-581.

Ball, O.J-P.; Miles, C.O.; Prestidge, R.A. 1997. Ergopeptine alkaloids and Neotyphodium lolii-mediated resistance in perennial ryegrass against adult Heteronychus arator (Coleoptera: Scarabaeidae). Journal of Economic Entomology 90: 1382-1391.

Ball, O.J-P.; Coudron, T.A.; Tapper, B.A.; Davies, E.; Trently, D.; Bush, L.P.; Gwinn, K.D.; Popay, A.J. 2006. Importance of host plant species, Neotyphodium endophyte isolate, and alkaloids on feeding by Spodoptera frugiperda (Lepidoptera: Noctuidae) larvae. Journal of Economic Entomology 99: 1462-1473.

Bouton, J.H.; Easton, H.S. 2004. Endophytes in forage cultivars. pp. 327-340. In: Neotyphodium in Cool-Season Grasses. Eds. Roberts, C.A.; West, C.P.; Spiers, D.E., Blackwell Publishing, Ames, IA.

Bush, L.P.; Fannin, F.F.; Siegel, M.R.; Dahlman, D.L.; Burton,
H.R. 1993. Chemistry, occurrence and biological effects of saturated pyrrolizidine alkaloids associated with endophytegrass interactions. Agriculture, Ecosystems and Environment 44: 81-102.

Cao, M.; Johnson, L.; Johnson, R.; Koulman, A.; Lane, G.A.; Rasmussen, S. 2007. Joint analyses of transcriptomic and metabolomic data to probe ryegrass-endophyte symbiosis. Pp 195 In: Proceedings of the $6^{\text {th }}$ International Symposium on Fungal Endophytes of Grasses. Grassland Research and Practice Series No. 13. New Zealand Grassland Association.

Easton, H.S.; Christensen, M.J.; Eerens, J.P.J.; Fletcher, L.R.; Hume, D.E.; Keogh, R.G.; Lane, G.A.; Latch, G.C.M.; Pennell, C.G.L.; Popay, A.J.; Rolston, M.J.; Sutherland, B.L.; Tapper, B.A. 2001. Ryegrass endophyte: a New Zealand Grassland success story. Proceedings of the New Zealand Grassland Association 63: 37-46.

Faville, M.J.; Koulman, A.; Briggs, L.; Cao, M.; Podmore, C.; Abraham, D. 2007. Exploring endophyte compatibility in perennial ryegrass. Pp 143 In: Proceedings of the $6^{\text {th }}$ International Symposium on Fungal Endophytes of Grasses. Grassland Research and Practice Series No. 13. New Zealand Grassland Association.

Fletcher, L.R.; Harvey, I.C. 1981. An association of a Lolium endophyte with ryegrass staggers. New Zealand Veterinary Journal 29: 185-186.

Gallagher, R.T.; White, E.P.; Mortimer, P.H. 1981. Ryegrass staggers: isolation of potent neurotoxins lolitrem A and lolitrem B from staggers-producing pastures. New Zealand Veterinary Journal 29: 189-190.

Garner, G.B.; Rottinghaus, G.B.; Cornell, C.N.; Testereci, H. 1993. Chemistry of compounds associated with endophyte / grass interactions: ergovaline- and ergopeptine-related alkaloids. Agriculture, Ecosystems and Environment 44: 65-80. Gatenby, W.A.; Munday-Finch, S.C.; Wilkins, A.L.; Miles, C.O. 1999. Terpendole M, a novel indole-diterpenoid isolated from Lolium perenne infected with the endophytic fungus Neotyphodium lolii. Journal of Agricultural and Food Chemistry 47: 1092-1097.

Hoveland, C.S.; Schmidt, S.P.; King, C.C.J.; Odom, J.W.; Clark, E.M.; McGuire, J.A.; Smith, L.A.; Grimes, H.W.; Holliman, J.L. 1980. Association of Epichloe typhina fungus and steer performance on tall fescue pasture. Agronomy Journal 72: 1064-1065.

Johnson, L.; Steringa, M.; Koulman, A.; Christensen, M.; Johnson, R.; Voisey, C.; Bryan, G.; Lamont, I.; Rasmussen, S. 2007. Biosynthesis of an extracellular siderophore is essential for maintenance of mutualistic endophyte-grass symbioses. Pp 177 In: Proceedings of the $6^{\text {th }}$ International Symposium on Fungal Endophytes of Grasses. Grassland Research and Practice Series No. 13. New Zealand Grassland Association.

Koulman, A.; Lane, G.A.; Christensen, M.J.; Fraser, K.; Tapper, B.A. 2006a. Peramine and other fungal alkaloids are exuded in the guttation fluid of endophyte-infected grasses. Phytochemistry: in press.

Koulman, A.; Tapper, B.A.; Fraser, K.; Cao, M.; Lane, G.A.; Rasmussen, S. 2006b. High throughput direct infusion ion trap mass spectrometry: a new method for metabolomics. Rapid Communications in Mass Spectrometry: in press.

Koulman, A.; van Gils, M.J.; Lane, G.A.; Christensen, M.J.; Fraser, K.; Tapper, B.A. 2007. The analysis of fungal alkaloids in plant fluids. Pp 173 In: Proceedings of the $6^{\text {th }}$ International Symposium on Fungal Endophytes of Grasses. Grassland Research and Practice Series No. 13. New Zealand Grassland Association. 
Lane, G.A.; Christensen, M.J.; Miles, C.O. 2000. Chapter 14. Coevolution of fungal endophytes with grasses: the significance of secondary metabolites. pp. 341-388. In: Microbial Endophytes. Eds. Bacon, C. W.; White, J. F., Marcel Dekker, New York.

Miles, C.O.; di Menna, M.E.; Jacobs, S.W.L.; Garthwaite, I.; Lane, G.A.; Prestidge, R.A.; Marshall, S.L.; Wilkinson, H.H.; Schardl, C.L.; Ball, O.J-P.; Latch, G.C.M. 1998. Endophytic fungi in indigenous Australasian grasses associated with toxicity to livestock. Applied and Environmental Microbiology 64: 601-606.

Munday-Finch, S.C.; Wilkins, A.L.; Miles, C.O. 1998. Isolation of lolicine A, lolicine B, lolitriol, and lolitrem N from Lolium perenne infected with Neotyphodium lolii and evidence for the natural occurrence of 31-epilolitrem $\mathrm{N}$ and 31-epilolitrem F. Journal of Agricultural and Food Chemistry 46: 590-598.

Panaccione, D.G.; Tapper, B.A.; Lane, G.A.; Davies, E.; Fraser, K. 2003. Biochemical outcome of blocking the ergot alkaloid pathway of a grass endophyte. Journal of Agricultural and Food Chemistry 51: 6429-6437.

Panaccione, D.G.; Cipoletti, J.R.; Sedlock, A.B.; Blemings, K.P.; Schardl, C.L.; Machado, C.; Seidel, G.E. 2006a. Effects of ergot alkaloids on food preference and satiety in rabbits, as assessed with gene-knockout endophytes in perennial ryegrass (Lolium perenne). Journal of Agricultural and Food Chemistry 54: 4582-4587.

Panaccione, D.G.; Kotcon, J.B.; Schardl, C.L.; Johnson, R.D.; Morton, J.B. 2006b. Ergot alkaloids are not essential for endophytic fungus-associated population suppression of the lesion nematode, Pratylenchus scribneri, on perennial ryegrass. Nematology 8: 583-590.

Pennell, C.G.L.; Popay, A.J.; Ball, O.J-P.; Hume, D.E.; Baird, D.B. 2005. Occurrence and impact of pasture mealybug (Balanococcus poae) and root aphid (Aploneura lentisci) on ryegrass (Lolium spp.) with and without infection by Neotyphodium fungal endophytes. New Zealand Journal of Agricultural Research 48: 329-337.

Popay, A.J.; Baltus, J.G. 2001. Black beetle damage in perennial ryegrass infected with AR1 endophyte. Proceedings of the New Zealand Grassland Association 63: 267-271.

Popay, A.J.; Bonos, S.A. 2005. Biotic responses in endophytic grasses. pp. 163 -185. In: Neotyphodium in Cool Season Grasses. Eds. Roberts, C.A.; West, C.P.; Spiers, D.E., Blackwell Publishing, Ames, IA.

Popay, A.J.; Silvester, W.B.; Gerard, P.J. 2004. New endophyte isolate suppresses root aphid, Aploneura lentisci in perennial ryegrass. pp. 317. In: Proceedings of the 5th International Symposium on Neotyphodium/Grass Interactions. Eds. Kallenbach, R.; Rosenkrans, C.J.; Lock,T.R. Fayetteville, Arkansas.

Popay, A.J.; Wyatt, R.T. 1995. Resistance to Argentine stem weevil in perennial ryegrass infected with endophytes producing different alkaloids. pp. 229-236. In: Proceedings of the $48^{\text {th }}$ New Zealand Plant Protection Society Conference.

Raamsdonk, L.M.; Teusink, B.; Broadhurst, D.; Zhang, N.S.; Hayes, A.; Walsh, M.C.; Berden, J.A.; Brindle, K.M.; Kell, D.B.; Rowland, J.J.; Westerhoff, H.V.; van Dam, K.; Oliver, S.G. 2001. A functional genomics strategy that uses metabolome data to reveal the phenotype of silent mutations. Nature Biotechnology 19: 45-50.

Rowan, D.D.; Gaynor, D.L. 1986. Isolation of feeding deterrents against Argentine stem weevil from ryegrass infected with the endophyte Acremonium loliae. Journal of Chemical Ecology 12: 647-658.

Siegel, M.R.; Bush, L.P. 1996. Defensive chemicals in grassfungal endophyte associations. pp. 81-119. In: Phytochemical Diversity and Redundancy in Ecological Interactions. Eds. Romeo, J. T.; Saunders, J. A.; Barbosa, P., Plenum, New York.

Tanaka, A.; Tapper, B.A.; Popay, A.; Parker, E.J.; Scott, B. 2005. A symbiosis expressed non-ribosomal peptide synthetase from a mutualistic fungal endophyte of perennial ryegrass confers protection to the symbiotum from insect herbivory. Molecular Microbiology 57: 1036-1050.

Tanaka, A.; Christensen, M.J.; Takemoto, D.; Park, P.; Scott, B. 2006. Reactive oxygen species play a role in regulating a fungus-perennial ryegrass mutualistic interaction. Plant Cell 18: 1052-1066.

Tapper, B.A.; Christensen, M.J.; Fletcher, L.R.; Lane, G.A.; Latch, G.C.M.; Popay, A.J.; Easton, H.S. 2002. 'Grass Endophytes' NZ patent application No. 521653 dated 27/9/02.

Tapper, B.A.; Lane, G.A. 2004. Janthitrems found in a Neotyphodium endophyte of perennial ryegrass. Poster 301. In: Proceedings of 5th International symposium on Neotyphodium/Grass Interactions. Eds. Kallenbach, R.; Rosenkrans, C.J.; Lock, T.R. Fayetteville, Arkansas.

Towers, N.R. 1997. Endophyte toxin research at the Ruakura Agricultural Research Centre. pp. 167-171. In: Proceedings 19, Mykotoxin-Workshop.Eds. Märtlbauer, E.; Usleber, E. Society for Mycotoxin Research, Munich.

Wilkinson, H.H.; Siegel, M.R.; Blankenship, J.D.; Mallory, A.C.; Bush, L.P.; Schardl, C.L. 2000. Contribution of fungal loline alkaloids to protection from aphids in a grass-endophyte mutualism. Molecular Plant-Microbe Interactions 13: 10271033.

Young, C.A.; Felitti, S.; Shields, K.; Spangenberg, G.; Johnson, R.D.; Bryan, G.T.; Saikia, S.; Scott, B. 2006. A complex gene cluster for indole-diterpene biosynthesis in the grass endophyte Neotyphodium lolii. Fungal Genetics and Biology 43: 679-693.

Zhang, Z.; Ober, J.A.; Kliebenstein, D.J. 2006. The gene controlling the quantitative trait locus EPITHIOSPECIFIER MODIFIER1 alters glucosinolate hydrolysis and insect resistance in Arabidopsis. The Plant Cell 18: 1524-1536. 